
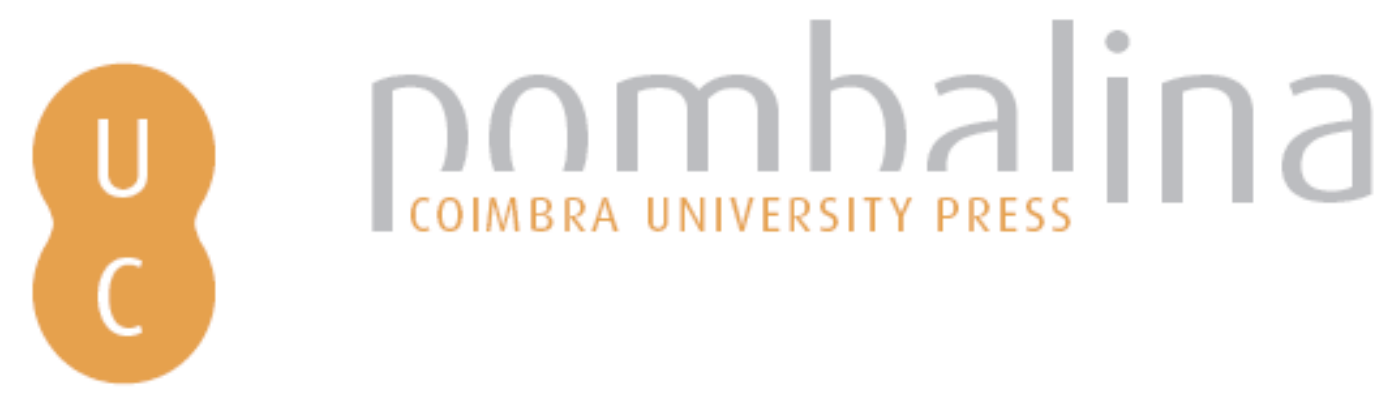

\title{
Uma análise crítica dos conceitos de análise de fragilidades ambientais e de avaliação ambiental integrada
}

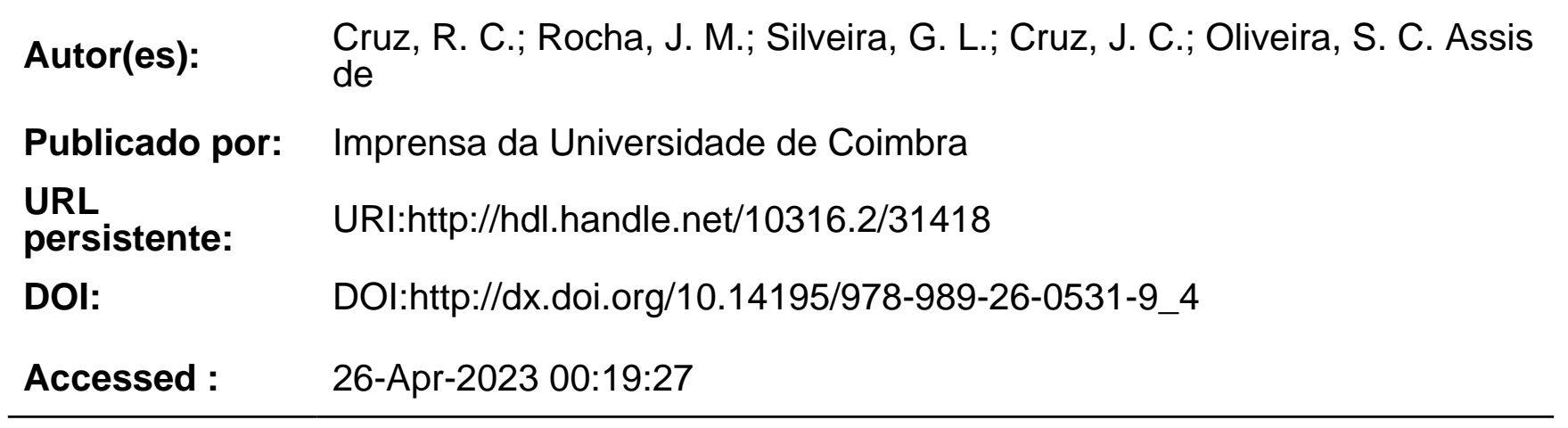

A navegação consulta e descarregamento dos títulos inseridos nas Bibliotecas Digitais UC Digitalis, UC Pombalina e UC Impactum, pressupõem a aceitação plena e sem reservas dos Termos e Condições de Uso destas Bibliotecas Digitais, disponíveis em https://digitalis.uc.pt/pt-pt/termos.

Conforme exposto nos referidos Termos e Condições de Uso, o descarregamento de títulos de acesso restrito requer uma licença válida de autorização devendo o utilizador aceder ao(s) documento(s) a partir de um endereço de IP da instituição detentora da supramencionada licença.

Ao utilizador é apenas permitido o descarregamento para uso pessoal, pelo que o emprego do(s) título(s) descarregado(s) para outro fim, designadamente comercial, carece de autorização do respetivo autor ou editor da obra.

Na medida em que todas as obras da UC Digitalis se encontram protegidas pelo Código do Direito de Autor e Direitos Conexos e demais legislação aplicável, toda a cópia, parcial ou total, deste documento, nos casos em que é legalmente admitida, deverá conter ou fazer-se acompanhar por este aviso.

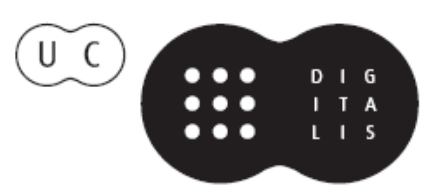





\title{
UMA ANÁLISE CRÍTICA DOS CONCEITOS DE ANÁLISE DE FRAGILIDADES AMBIENTAIS E DE AVALIAÇÃO AMBIENTAL INTEGRADA
}

\author{
A CRITICAL ANALYSIS OF THE CONCEPTS \\ OF ENVIRONMENTAL FRAGILITY ANALYSIS AND \\ INTEGRATED ENVIRONMENTAL ASSESSMENT
}

\author{
R. C. Cruz ${ }^{1}$, J. M. Rocha ${ }^{1}$, G. L. Silveira ${ }^{2}$, J. C. Cruz ${ }^{2} \&$ S. C. Assis de Oliveira ${ }^{3}$
}

\begin{abstract}
Resumo - Neste artigo procura-se reconstruir a história conceitual da análise de fragilidades ambientais, desde a sua origem nos estudos da geomorfologia, até a sua atualização com base nos conceitos de ecossistema total humano (ETH) e de estabilidade de sistemas, na esteira da evolução da Ecologia de Paisagem. Na sequência, se discutem as implicações desta evolução conceitual na abordagem da Avaliação Ambiental Integrada (AAI), tomando-se como estudo de caso a aplicação da AAI no planejamento ambiental de bacias hidrográficas e seus conflitos com as políticas setoriais de irrigação e de geração de energia elétrica. Discute-se os limites da inserçáo de indicadores institucionais nos modelos de AAI e como esta deve ser entendida como processo, passando por fases de análise de fragilidades ambientais, tendo como objeto de estudo o ETH, considerando a análise de diferentes cenários de intervençóes antrópicas e chegando na análise das consequências de diferentes cenários de tomada de decisóes. Alerta-se quanto ao risco da internalizaçáo de conflitos intra e interinstitucionais nos modelos, que pode levar ao enfraquecimento do processo de negociação que deve haver entre os diferentes atores institucionais e comunitários, ao fortalecimento da tecnocracia e ao possível aprofundamento dos conflitos, com prejuízos à qualidade de vida e à sustentabilidade.
\end{abstract}

Palavras-chave - Avaliação ambiental integrada; Fragilidades ambientais; Estabilidade; Sustentabilidade

\footnotetext{
${ }^{1}$ Campus de São Gabriel, Fundação Universidade Federal do Pampa, Av. Antônio Trilha, 1847 - São Gabriel - RS - CEP: 97300-000, Brasil; rafaelcruz@unipampa.edu.br; jefferson.rocha@unipampa.edu.br.

${ }^{2}$ DESA, UFSM, Santa Maria - RS - Brasil; geraldo.ufsm@gmail.com; jussaracruz@pesquisador.cnpq.br.

${ }^{3}$ Colégio Tiradentes de São Gabriel, São Gabriel - RS - Brasil; soniacadeoliveira@gmail.com
} 
Abstract - This article seeks to reconstruct the conceptual history of environmental fragility analysis, since its origin in studies of geomorphology, until its update based on the concepts of total human ecosystem (THE) and stability of systems in the wake of Landscape Ecology developments. Following, we discuss the implications of this conceptual evolution in the approach of Integrated Environmental Assessment (IEA), taking as case study the application of IEA in the environmental planning of watersheds and their conflicts with the irrigation and generation of electricity sector policies. It discusses the limits of inclusion of institutional indicators in the models of IEA and how it should be understood as a process, going through phases of fragility environmental analysis, where the object of study, the THE, through analysis of different scenarios of human interventions and arriving in the analysis of the consequences of different scenarios for decision making. We alert about the risk of internalization of intra and inter-institutional conflicts in the models, which can lead to weakening of the negotiation process that should exist between different institutions and community, strengthening the technocracy and the possible deepening of the conflict, with damages to quality of life and sustainability.

Keywords - Integrated environmental assessment; Environmental fragility; stability; sustainability

\section{1 - Introdução}

Neste artigo procura-se reconstruir a história conceitual da análise de fragilidades ambientais, desde a sua origem nos estudos da geomorfologia, até a sua atualização com base nos conceitos de ecossistema total humano (ETH) e de estabilidade de sistemas, na esteira da evolução da Ecologia de Paisagem. Na sequência, se discutem as implicaçôes desta evolução conceitual na abordagem da Avaliação Ambiental Integrada (AAI), tomando-se como estudo de caso a aplicação da AAI no planejamento ambiental de bacias hidrográficas e seus conflitos com as políticas setoriais de irrigação e de geração de energia elétrica.

\section{2 - Sustentabilidade e estabilidade}

Distinguir a sustentabilidade natural da sustentabilidade socioeconômica, apesar de ser útil para delimitar campos de reflexão, pode induzir a graves desvios de interpretação da realidade, na medida de fazer relaçóes estanques entre dinâmicas sociais e ecológicas, o risco é criar-se dicotomias didaticamente/cientificamente explicativas, que não dão conta da real interdependência das duas ordens da realidade (ROCHA, 2011).

Porém, apesar destes riscos, essa dicotomia fundamenta a quase totalidade das acepçôes de "sustentabilidade" no meio acadêmico. Pois geralmente a sustentabilidade do meio natural é pensada como passando por proteção das perturbaçóes criadas pelas atividades antrópicas, já a sustentabilidade socioeconômica é encarada como um tipo de desenvolvimento que não desgaste o meio natural. Assim uma "sustentabilidade" efetiva seria o resultado de uma vinculação da dinâmica destes dois sistemas.

Aqui considera-se que esta dicotomia náo é capaz de dar conta da maneira como, tanto as ciências naturais como as ciências sociais, encaram as relaçôes sustentáveis entre sociedade e natureza. 
A própria noção de "natureza", como se esta fosse pensável enquanto realidade em si, é uma abstração. A quase totalidade dos ambientes naturais que se observa é fruto da ação antrópica. Neste sentido é preciso considerar não só as escalas de tempo e de espaço, mas a relaçáo que as sociedades possuem com o meio natural a sua volta. Alguns sistemas podem nem "perceber" certas perturbaçóes causadas por sociedades tradicionais, por exemplo. A escala da perturbação causada é muito pequena em relação ao sistema total. Além disto, determinados fenômenos da dinâmica natural ainda não são influenciados pela ação do homem, mas o influenciam grandemente, e configuram o ambiente, como erupçóes vulcânicas, terremotos, el niño, la niña, entre outros.

Há que considerar que os homens, não só enquanto elos da cadeia trófica, mas como seres sociais, participam dos processos de formatação dos meios que ocupam. Pois, nas suas características presentes, bem como na sua história de transformaçóes e mudanças, esses meios náo podem ser analisados independentemente da história e das relaçóes em sociedade.

As dinâmicas sociais não podem ser encaradas como perturbadoras, mas sim como co-autoras dos meios naturais a sua volta. Evidentemente isso náo implica que as atividades humanas tenham sempre efeitos positivos sobre o meio: elas geralmente influenciam dinâmicas intrínsecas de mudança, e em muitos casos modificam profundamente e de maneira irreversível suas características.

Estes aspectos simplesmente confirmam que os dois sistemas (natural e social) estão continuamente em co-evolução interdependentes. Evolução no sentido de história e não como percurso finalizado ao longo de um eixo temporal.

Não se pode analisar corretamente a situação de um meio natural, bem como da sua evolução passada e futura, sem integrar a história de suas relações com as sociedades. Por exemplo, ao analisar-se os ecossistemas ocupados por pequenos agricultores, deve-se perceber o papel que as práticas de uso e de gestáo dos recursos desempenharam na formatação do meio natural (ROCHA, 2004).

Deve-se perceber também que o processo de apropriação dos recursos naturais ao longo do tempo, além de intensificar a exploração dos recursos naturais, foi realizado de forma injusta, pois a medida que o relacionamento do homem moderno/ europeu se aprofundava, ocorria a valorização econômica dos mais variados recursos naturais dos diversos lugares do planeta, tento como consequência sua degradação.

Assim a valoração e exploração dos ecossistemas fez parte da trajetória do desenvolvimento econômico de quase todos os lugares habitados.

\section{3 - Análise de fragilidades ambientais}

A análise de fragilidades ambientais, segundo MATOS FIERZ (2008) tem sua origem nos estudos dos geomorfólogos que gradualmente foram incorporando aspectos da teoria geral de sistemas e do equilíbrio dinâmico para conceituar fragilidade, remontando, principalmente aos estudos de HACK (1960, apud MATOS FIERZ, op.cit.), TRICART (1977) e ROSS (1994).

A ecodinâmica de TRICART (op.cit.) colocou em balanço a pedogênese e a morfogênese, classificando a morfodinâmica dos ambientes em três categorias: estáveis, intergrades e instáveis, em um continuo que tem predomínio da pedogênese sobre a morfogênese para 
estáveis e o inverso para instáveis, tendo um balanço próximo ao nulo nos intergrades. Neste esquema conceitual o ser humano aparece como agente causador da degradação.

ROSS (1994) desenvolvendo os conceitos de TRICART (1977), passou a definir

a elaboração de cartas de fragilidades ambientais: "A fragilidade dos ambientes naturais face as intervençôes humanas é maior ou menor em função de suas características genéticas. A princípio, salvo algumas regióes do planeta, os ambientes naturais mostram-se ou mostravam-se em estado de equilíbrio dinâmico até o momento em que as sociedades humanas passaram progressivamente a intervir cada vez mais intensamente na exploração dos recursos naturais" (ROSS, op.cit.). A mesma postura de Tricart se mantém na base conceitual. Visão dual opondo sociedade e natureza.

A base da definição de fragilidade ambiental é baseada no conceito de que "na natureza as trocas de energia e matéria se processam através de relaçôes em equilíbrio dinâmico" (ROSS, op.cit.). Fragilidade seria causada pela quebra deste equilíbrio pela ação humana. Incluiu os conceitos de instabilidade emergente (para as unidade ecodinâmicas instáveis, em vários graus e de instabilidade potencial, também em vários graus para as unidades ecodinâmicas estáveis que possuem uma previsibilidade natural para instabilidade e para a possibilidade de açôes antrópicas.

MATOS FIERZ (2008) fez ampla revisão da base conceitual da análise de fragilidades ambientais sob orientação de Ross. Demonstrou a importância da Teoria Geral de Sistemas na abordagem de Tricart, assim como o conceito de Equilíbrio Dinâmico de Hack aplicado para compreensão das formas do relevo. Com base nesta revisão definiu fragilidade ambiental como "a tendência de o relevo ser alterado de seu estado de equilíbrio dinâmico com facilidade, seja naturalmente seja por decorrência de fatores artificiais como os antrópicos. A fragilidade ambiental representa o limiar (threshold) entre o equilíbrio dinâmico e o não-equilíbrio nos ambientes antropizados" (MATOS FIERZ, op.cit.).

No entanto, o ser humano, nestas abordagens, aparece unicamente como agente de perturbaçóes ao ambiente, reproduzindo uma visão de mundo em que sociedade e natureza são vistas separadamente. A partir da ecologia de paisagem, rompe-se este paradigma, e a sociedade passa a ser vista como parte da natureza (NAVEH \& LIEBERMAN, 2001). Com base nestes conceitos, construiu-se uma visão ampliada do conceito de fragilidade ambiental, a partir da necessidade de incluir o conceito de sistemas auto-organizativos, de estabilidade e de resistência ou resiliência às perturbaçôes. Deste modo, fragilidade seria a qualidade de um determinado ETH para não perder sua estabilidade frente a um determinado regime de perturbaçóes. Neste contexto, o ser humano em sociedade, além dos meios físico e biótico, adquire um papel dual, ora sendo agente de perturbaçóes, ora sendo objeto do impacto ambiental (UNIPAMPA/UFSM, 2011).

As abordagens dos geomorfólogos foram construídas partindo-se do pressuposto que a base física condiciona todo o devir das relaçóes com os meios biótico e antrópico. No entanto, este pressuposto conceitual impediu uma evolução da análise de fragilidades ambientais de tal forma que permitisse uma abordagem efetivamente integrada da paisagem, com uma co-evolução dos meios físico, biótico e antrópico. Considere-se uma pergunta do tipo: qual a fragilidade de uma comunidade tradicional de pescadores frente a implantação de uma barragem? Como respondê-la se as abordagens anteriores somente consideram o ser humano como agentes de perturbação? Nesta análise, somente os empreendedores da barragem teriam lugar no modelo conceitual. Já na abordagem da ecologia de paisagem, a sociedade e sua cultura fazem parte de um mesmo hólon, são 
partes de um mesmo sistema, dentro do qual trocam energia, materiais e informação. De acordo com NAVEH \& LIEBERMAN (op.cit.) a ecologia de paisagem incorpora os avanços na teoria geral de sistemas, ocorridas com a física de sistemas termodinâmicos abertos e com a teoria dos sistemas auto-organizativos. Nestes sistemas, a identidade e a estabilidade do sistema são mantidas pelo desequilíbrio, que funciona como uma energia potencial que coloca o sistema em movimento. Nestes sistemas a ausência de mudança leva a não adaptação ao meio e a sua desintegração (transformação em outro sistema).

Outro problema conceitual refere-se ao fato de que a fragilidade deve ser referida a um determinado regime de perturbaçóes. Alguns sistemas podem ser resistentes a um determinado tipo de perturbações mas ser degradado por outro. Sendo assim, os estudos de fragilidade não podem ser genéricos. Um sistema não é frágil ou resistente "genericamente", mas frente a um determinado tipo de perturbação, que pode ser de qualquer tipo. $\mathrm{Na}$ análise de fragilidades ambientais, pode-se mapear a fragilidade de qualquer ambiente, mesmo que não existam proposiçóes concretas de intervençóes, desde que se defina que tipo de intervenção vai ser analisada e que tipo de interferência nos processos ambientais significativos para a estabilidade do sistema podem ocorrer.

\section{4 - Avaliação ambiental integrada no Brasil}

De acordo com CRUZ et al. (2010), "no Brasil, estes estudos iniciam com a necessidade de inserir a bacia hidrográfica como unidade de planejamento no sistema de licenciamento ambiental de barragens. Necessidade prevista na Resolução 01/86 do CONAMA (BRASIL, 1986), no entanto que não possuía instrumentos para sua implementaçáo". Deste modo, nasce de uma demanda de análise prévia de viabilidade ambiental de inventários para fins de construção de diretrizes para licenciamento ambiental de barragens.

Os primeiros estudos foram encomendados pela FEPAM (órgão ambiental do Estado do Rio Grande do Sul) em 2001, com o estudo da bacia dos rios Taquari-Antas (FEPAM/UFRGS, 2001), elaborado sob influência do relatório final da Comissão Mundial de Barragens (WCD, 2000) e que visava definir trechos de rios que deveriam ser permanecer livres de barramentos e hierarquizar os empreendimentos quanto à fragilidade ambiental dos trechos afetados, com objetivo de estabelecer diretrizes para o licenciamento para a bacia hidrográfica. Na mesma linha, com avanços metodológicos, foram efetuados os estudos da bacia dos rios Ijuí, Piratinim, Icamaquã e Butuí, afluentes do rio Uruguai (FEPAM/UFRGS, 2004) e da bacia dos rios Apuaê-Inhandava, afluentes do rio Pelotas (FEPAM/UFSM, 2005).

Em nível federal, o primeiro estudo de avaliação ambiental integrada (AAI), foi efetuado pela Empresa de Pesquisas Energéticas (EPE, 2007), vinculada ao Ministério das Minas e Energia, com Termo de Referência sob responsabilidade do Ministério do Meio Ambiente (MMA, 2005).

As dificuldades metodológicas de integração entre as abordagens de engenheiros (que coordenaram o estudo) e biólogos, marcou o primeiro estudo (FEPAM/UFRGS, 2001). No entanto, o estudo demonstrou a viabilidade de elaboraçáo de estudos que permitissem a elaboração de diretrizes ambientais para licenciamento de uma bacia hidrográfica. $\mathrm{Na}$ sequência, a FEPAM, na busca de aperfeiçoamento das abordagens integrativas, encomendou novo estudo (FEPAM/UFRGS, 2004), desta vez sob coordenação de biólogos 
vinculados ao Centro de Ecologia da UFRGS. Este grupo se aproximou do Grupo de Pesquisas em Gestáo de Recursos Hídricos da UFSM, que havia desenvolvido metodologia para análise de fragilidades/favorabilidades ambientais para seleção de locais para implantação de barragens de irrigação (SILVEIRA \& CRUZ, 2005) em situação de carência de dados, utilizando uma análise multicritério em ambiente de geoprocessamento para estruturar a integração de informaçóes. Esta linha acabou definindo uma das escolas de AAI, responsável, posteriormente pelo estudo da bacia dos rios Apuaê-Inhandava (FEPAM/UFSM, 2005) e pelo estudo do projeto FRAG-RIO (UNIPAMPA/UFSM, 2011). Cabe realçar que esta linha foi construída em ampla cooperaçáo entre as equipes executoras e o órgáo ambiental. Outro aspecto importante a ser realçado foi a independência das universidades para construir os estudos. A outra linha foi construída a partir da experiência acumulada pelos engenheiros do IPH/UFRGS, que coordenaram o estudo de 2001 e que vieram a orientar a elaboração do Termo de Referência para o estudo da EPE. As propostas deste Termo de Referência acabaram por ser adotadas na nova edição do Manual de Inventário de hidrelétricas da ELETROBRAS (ELETROBRAS, 2007), com o objetivo de "de integrar os procedimentos da AAI à metodologia dos estudos socioambientais que subsidia a seleção da melhor alternativa no Estudo de Inventário Hidroelétrico”. Ou seja, neste caso, a AAI passa a ser um instrumento da Política Energética, não da Política Ambiental. CRUZ et al. (2010) discutem as consequências deste movimento, demonstrando que a AAI somente pode ser efetiva na construção da sustentabilidade se for um instrumento da Política Ambiental e que seja prévia aos estudos de inventário, sendo coordenada e executada sob responsabilidade dos órgãos ambientais.

Assim, no Brasil, a AAI nasce da necessidade de internalização das "externalidades ambientais" dentro do processo de planejamento setorial, em especial dos setores que se utilizam intensivamente de barragens para sua atividade: irrigação e geração de energia elétrica. A construção desta abordagem acabou criando duas grandes escolas: uma construída a partir da relação entre ecólogos de paisagem com engenheiros hidrólogos (hidroecológica; e.g. UNIPAMPA/UFSM, 2011) e outra na relação entre engenheiros hidrólogos e economistas/gestores (hidroeconômica; e.g. TUCCI \& MENDES, 2006).

Dois momentos históricos confrontaram estas duas escolas: as dificuldades de integração metodológica que houve na execução do estudo do Taquari-Antas (FEPAM/UFRGS, 2001), já referido, e na análise do estudo da EPE (EPE, 2007) pelo Ministério do Meio Ambiente. Ao contrário do que ocorreu com todos os estudos anteriores, que possibilitaram aos órgãos ambientais a elaboração de diretrizes para o licenciamento de barragens em bacias hidrográficas, este estudo não permitiu ao MMA a elaboração destas diretrizes, o que o levou a encomendar o projeto FRAG-RIO ao grupo de pesquisa representante da outra escola, de forma independente em relação ao setor elétrico (execução por Universidades Federais). Os resultados da Etapa 1 do Projeto FRAG-RIO subsidiaram a elaboração das diretrizes de licenciamento para a bacia do rio Uruguai (MMA/IBAMA, 2010). A disputa entre MMA e MME está bem descrita em CRUZ et al. (2010).

Quais seriam as diferenças conceituais mais importantes entre estas escolas?

A primeira diferença conceitual refere-se à definição do objeto primário do estudo. $\mathrm{O}$ que se pretende hierarquizar: trechos de rios ou empreendimentos? A escola hidroeconômica, consolidada institucionalmente no Manual de Inventário da ELETROBRAS (ELETROBRAS, 2007), define que os empreendimentos são o objeto primário dos estudos. A escola hidroecológica (UNIPAMPA/UFSM, 2011) define que o objeto 
primário é o ambiente, no caso de fragilidade frente à fragmentação de rios provocada pelas barragens, os trechos de rios de uma bacia hidrográfica. Esta diferença é consequência das diferentes visóes da AAI como parte da Política Energética ou Ambiental. A grande vantagem da abordagem da escola hidroecológica é que a AAI pode preceder os estudos de inventário, uma vez que náo há necessidade de definiçáo prévia dos empreendimentos para estudar a fragilidade dos trechos de rios para barragens. Esta vantagem também tem como corolário a flexibilidade para o uso dos órgãos ambientais. Atualmente, os inventários estão constantemente sendo atualizados, o que torna os estudos focados em empreendimentos rapidamente obsoletos. Quando o foco é nos trechos de rios, basta sobrepor os novos inventários aos trechos respectivos e verificar as fragilidades dos mesmos. Logicamente, como o ambiente está em permanente mudança, também os estudos efetuados com foco nos trechos de rios devem ser atualizados dentro de uma abordagem de manejo adaptativo.

Outra consequência desta diferença está na solução para espacialização das duas abordagens. A escola hidroeconômica apregoa que a espacialização dos dados deve se dar em setores, com o objetivo de avaliar os impactos cumulativos e sinérgicos. TUCCI \& MENDES (2006) recomendam que a subdivisão da área de estudo deve englobar grupos de empreendimentos, "devendo-se evitar uma grande fragmentação utilizando no mínimo 3 (três) e no máximo 6 (seis) subdivisôes”. Deste modo, a setorização da bacia é definida à priori com base na distribuição dos empreendimentos. Do ponto de vista de discretização das fragilidades para fins de hierarquização dos setores, trabalhar com 3 a 6 setores em bacias com mais de $100.000 \mathrm{~km}^{2}$, como a bacia do rio Uruguai, resulta em setores muito grandes, englobando, cada um deles, várias sub-bacias, com ordem de grandeza, cada uma de dezena de milhares de $\mathrm{km}^{2}$. Neste tipo de abordagem, definir trechos de rios que devem ser mantidos livres de barramentos náo é possível, assim como responder a seguinte pergunta: considerando dois trechos de rios dentro de um mesmo setor, qual deles possui maior fragilidade perante a implantação de barragens? Já a escola hidroecológica propóe que a análise de fragilidades ambientais deve ser efetuada pixel a pixel, em escala apropriada para a dimensão da bacia hidrográfica (1:250.000 para a bacia do rio Uruguai), de modo que a espacialização, ou zoneamento das fragilidades, possa ser obtida a posteriori e os trechos de rios possam ser hierarquizados. Este tipo de abordagem permite a definiçáo de trechos que devem permanecer livres de barramentos para responder a pergunta acima explicitada.

A segunda grande diferença conceitual refere-se a forma de inserção dos conflitos na AAI. Na escola hidroeconômica a AAI é vista como um estudo que possui como resultados "medidas preventivas como diretrizes, recomendaçóes para estudos complementares e elementos fundamentais para os EIAs" (TUCCI \& MENDES, 2006). Já a escola hidroecológica defende que os estudos da AAI devem subsidiar os órgãos ambientais para que estes possam elaborar as diretrizes: "são resultados orientativos para as negociaçóes e processos de tomada de decisão: o estudo subsidia a decisão, não decide!” (UNIPAMPA/UFSM, 2011).

Para se compreender a dimensão desta diferença, deve-se analisar as diferentes definiçôes de AAI.

Para a Agência Ambiental Européia, AAI é "o processo interdisciplinar e social, unindo conhecimento e ação em contextos de decisão e políticas públicas, e que visa a identificação, análise e avaliação de todos os processos naturais e humanos e suas interaçóes que determinam tanto o estado atual e futuro da qualidade ambiental e dos 
recursos, em adequadas escalas espaciais e temporais, facilitando assim a elaboração e implementação de políticas e estratégias" (EEA, 2012). Esta mesma definição é citada por TUCCI \& MENDES (2006).

Para o Programa das Naçôes Unidas para o Meio Ambiente, a "avaliação ambiental integrada e seu relatório tentam mostrar as relaçóes de causa-efeito entre a ação humana e natural no ambiente e, por sua vez, a resultante mudança no estado do ambiente e bem-estar humano. O resultado final da avaliação ambiental deve ser mais do que apenas saber o estado do ambiente. Deve dar aos políticos, e às outras partes interessadas, algumas orientaçôes sobre a melhor forma de gerenciar o ambiente" (UNEP, 2003).

Combinando-se as duas definiçóes, observa-se que a AAI deve ocorrer em contextos de decisão e políticas públicas. Ou seja, é um processo, em que os estudos de AAI são somente a primeira etapa de um processo de AAI que deve ser negociado entre todas as partes envolvidas nos conflitos, em fórum adequado, para facilitar a elaboração e implementação de políticas e estratégias. No Brasil, os conflitos inter-institucionais entre as políticas setoriais não possuem um fórum específico e institucionalizado para negociação das demandas conflitantes. Na prática, estas políticas públicas tem seus conflitos intra-governamentais decididos em reunióes entre os ministérios mediadas pela Casa Civil, sem participação ampla da sociedade, muitas vezes sem consenso, resultando em trocas ministeriais. Uma forma de viabilizar a plena implantação do processo de AAI é institucionalizar que estes conflitos devem ser negociados através de reuniôes conjuntas, paritárias, dos Conselhos criados pelas respectivas Leis que criaram as políticas públicas setoriais, cujo funcionamento e regras devem ser regulamentados em lei. Isto traria transparência e poderia viabilizar o processo de AAI em sua forma ampla e irrestrita. Para tal, os estudos de AAI devem ser conduzidos pela política ambiental, mas as negociaçóes dos conflitos devem se dar em um fórum mais amplo.

\section{4 - Consideraçóes finais}

As diferenças entre as escolas remontam ao objeto da AAI: o ambiente (hidroecológica) ou o conjunto de intervençôes (hidroeconômica) e como inserir os conflitos no processo: inseridos no modelo (hidroeconômica) ou objeto de negociação posterior (hidroecológica). Recomenda-se a que os estudos de AAI limitem-se a subsidiar o processo de AAI, deixando a negociação dos conflitos e a construção de diretrizes negociadas de planejamento integrado, para definição de políticas públicas para fóruns institucionalizados e transparentes (a serem criados). A internalização da AAI como instrumento da política energética esvazia a AAI da sua essência. Também se recomenda a não internalização dos conflitos nos estudos de AAI, pois existe risco de que este processo possa levar ao enfraquecimento do processo de negociação que deve haver entre os diferentes atores institucionais e comunitários, ao fortalecimento da tecnocracia e ao possível aprofundamento dos conflitos, com prejuízos à qualidade de vida e à sustentabilidade. A aproximação das escolas hidroecológica e hidroeconômica, necessária, passa pela solução destas diferenças conceituais e, para ser colocada em prática, dependendo de um aperfeiçoamento institucional que ainda está longe de acontecer.

Agradecimentos - à FINEP e ao CNPq pelo financiamento do projeto FRAG-RIO. 


\section{Referências Bibliográficas}

BRASIL (1986) - Resolução CONAMA No 1, de 23 de janeiro de 1986. Diário Oficial da União, de 17 de fevereiro de 1986, Seção 1: 2548-2549.

CRUZ, R. C.; SILVEIRA, G. L.; VILELLA, F. S.; CRUZ, J. C. \& OLIVEIRA, S. C. A. (2010) - A avaliação ambiental integrada de bacias hidrográficas como instrumento de negociação entre a política ambiental e políticas setoriais: o caso da análise de fragmentação do rio Uruguai por barragens. In: Actas. VI Seminário Latino-Americano de Geografia Física, II Seminário Ibero-Americano de Geografia Física, Universidade de Coimbra. http://www.uc.pt/fluc/cegot/VISLAG/actas/tema3/rafael_cruz. (Consultado em 2012.02.10).

EEA (2012) - Integrated environmental assessment http://glossary.eea.europa.eu/EEAGlossary/I/integrated_ environmental_assessment (Consultado em 2012.02.10).

ELETROBRAS (2007) - Manual de Inventário Hidrelétrico de Bacias Hidrográficas, 3 ed. http://www.eletrobras.com/ELB/data/Pages/LUMISF99678B3PTBRIE.htm. (Consultado em 2010/03/30).

EPE (2007) - Avaliação Ambiental Integrada (AAI) dos Aproveitamentos Hidrelétricos da Bacia Hidrográfica do Rio Uruguai. Relatório Final. Consórcio Themag/Andrade \& Canellas/Bourscheid, Brasília: 437p.

FEPAM/UFRGS (2001) - Diagnóstico Ambiental da Bacia do Taquari-Antas/RS: Diretrizes Regionais para o Licenciamento Ambiental das Hidrelétricas. FEPAM/UFRGS, Porto Alegre: 40p.

FEPAM/UFRGS (2004) - Análise de Fragilidades Ambientais e da Viabilidade de Licenciamento de Aproveitamentos Hidrelétricos das Bacias Hidrográficas dos Rios Ijuí e Butuí-Piratinim-Icamaquã, Região Hidrográfica do Rio Uruguai - RS. FEPAM/UFRGS, Porto Alegre: 138p.

FEPAM/UFSM (2005) - Análise de Fragilidades Ambientais da Bacia Hidrográfica dos rios Apuaê-Inhandava, situada na Região Hidrográfica do rio Uruguai. Relatório Técnico Final, FEPAM/UFSM, Santa Maria: 86p.

HACK, J.T. (1960) - Interpretation of erosional topography in humid temperate regions. American Journal of Science, Bradley Volume,v. 258, p. 80-97,

MATOS FIERZ, M. S. (2008) - As abordagens sistêmicas e do equilíbrio dinâmico na análise da fragilidade ambiental do litoral do estado de São Paulo: contribuição à geomorfologia das planícies costeiras. Tese de Doutorado, Departamento de Geografia, Universidade de São Paulo: 394 p.

MMA (2005) - Ministério do Meio Ambiente. Termo de Referência para o Estudo de Avaliação Ambiental Integrada dos Aproveitamentos Hidrelétricos da Bacia do Rio Uruguai. Brasília: MMA, 2005. 35 p. Disponível em: http://www.epe.gov.br/MeioAmbiente/Documents/MeioAmbiente_2/AAI\%20Rio\%20Uruguai \%20-\%20Termo\%20de\%20Refer\%C3\%AAncia.pdf. Acesso em 10/02/2012.

MMA \& IBAMA (2010) - Portaria Conjunta no. 297, de 9 de agosto de 2010. Diário Oficial da União, Seção 1, 152: 164 .

NAVEH, Z. \& LIEBERMAN, A. S. (2001) - Ecología de Paisajes: teoria y aplicación. Editorial Facultad de Agronomia, Buenos Aires: 571 p.

ROCHA, J.M. (2004) - A Sustentabilidade Desfocada: as lógicas das políticas de desenvolvimento rural para áreas de proteção ambiental (APAs) - O caso de Guaraqueçaba - PR-. Tese de doutorado. Programa de Pós-Graduação em Meio Ambiente e Desenvolvimento, Universidade Federal do Paraná: 234 p.

ROCHA, J.M. (2011) - Sustentabilidade em questão: Economia, Sociedade e Meio Ambiente. Paco Editorial, Jundia-SP: 167 p.

ROSS, J. L. S. (1994) - Análise empírica da fragilidade dos ambientes antropizados. Revista do Departamento de Geografia, São Paulo, 8: 63-74.

SILVEIRA, G. L. \& CRUZ, J. C. (orgs.) (2005) - Seleção ambiental de barragens: análise de favorabilidades ambientais em escala de bacia hidrográfica. Editora da UFSM/ABRH, Santa Maria: 388 p.

TRICART, J. (1977) - Ecodinâmica. Supren/IBGE, Rio de Janeiro: 97 p. 
TUCCI, C. E. M. \& MENDES, C. A. (2006) - Avaliação ambiental integrada de bacia hidrográfica. MMA, Brasília: 302 p.

UNEP (2003) - Africa Environment Information Network (AEIN): Framework for Capacity Building in Integrated Environmental Assessments and Reporting in Africa. United Nations Environment Programme, Nairobi. http://www.unep.org/dewa/africa/docs/en/AEIN_framework_Document.pdf. (Consultado em 2012.02.10).

UNIPAMPA/UFSM (2011) - Desenvolvimento metodológico e tecnológico para a avaliação ambiental integrada aplicada ao processo de análise de viabilidade de hidrelétricas - FRAG-RIO. Relatório da Etapa 2. MMA/FATEC/UNIPAMPA/UFSM, Santa Maria: 270 p.

WCD (2000) - Dams and Development: a new framework for decision-making. The Report of The World Commission on Dams. Earthscan Publications Ltd, London: 404 p. 